\title{
Exposure Therapy by Virtual Reality and Its Monitoring by Biofeedback
}

\author{
Šlepecký, M.1 , Škobrtal, P. ${ }^{2,3}$, Novotný, M. ${ }^{3}$, Bazinková, E. ${ }^{3}$, Kotianová, A.1 \\ ${ }^{1}$ Department of Psychological Sciences, Faculty of Social Sciences and Health Care Constantine The Philosopher University in Nitra, \\ Kraskova 1, 94974 NITRA, Slovakia \\ 2 Ostravská univerzita, Ostrava, Česká republika \\ ${ }^{3}$ Centrum duševního zdraví, Jeseník, Česká republika
}

\section{Summary}

Utilisation of instrumentation within exposure therapy enables a client to get a continuous feedback on the function of client's autonomous nervous system. Thanks to that the person may increase cognitive control by his or her own autonomous nervous system reactions. By biofeedback In other words, the client gets information on possible maladaptive responses in real time and he/she can learn how to reacts adaptively.

This study utilises technique of "virtual reality" for exposing fearful scenarios that can be hardly simulated in reality.

Key words: Exposure training, biofeedback, virtual reality

\section{Introduction}

Exposure as a therapeutic method is very often used to the phobic person to the stimuli that they are afraid. Specific phobias are maintained because of avoidance of the phobic stimuli and emotions connected with them so that the individual does not have the opportunity to learn that he/she can stand them, that the fear will extinguished on its own without necessity to avoid or escape, and that his/her feared outcomes often do not come true or are not as dreadful as they visualize. Avoidance can occur either by not entering a situation at all or by entering the situation but not experiencing it fully (e.g., because of taking drugs). Exposure therapies are thus planned to encourage the person to enter feared circumstances (either in reality or through imagination) and to try to remain in those situations till the fear is considerably lessened.

Virtual reality exposure uses a computer program to generate the phobic situation (e.g., experiencing take off, be present with a spider, overseeing surrounding from the high tower), and integrates real-time computer graphics with various body tracking devices. This therapy appears to be useful for phobias that may be difficult to treat in vivo; namely being in the plain or height phobias, but more studies are needed to demonstrate its efficacy for a broader range of phobia subtypes.

\section{Teoretical consideration}

One cognitive behaviour therapy pillars comes from classical I. P. Pavlov's experiments with conditioning. Pavlov and many other scientists proved that many emotions and patterns of behaviour have been learn on a base of classical conditioning. From behavioural point of view, all normal and abnormal behaviours is acquired by learning principles. Abnormal behaviour means that person did not learn strategies how to cope with current live situations or lapsed into dysfunctional patterns of behaviour. Behavioural therapy then applies principles of classical and operant conditioning to the treatment of mental disorders and maladaptive behaviour. The goal of the therapy is to change conditioned dysfunctional patterns of patient's behaviour and to replace them by more adaptive forms. For this purpose two methods - exposure therapy and operant conditioning were created (Meyers, 2008).

Exposure therapy is frequently used in various anxiety disorders (social fobias, agoraphobia, panic disorders, obsessive-compulzive disorders) and it is part of the cognitive behavioural techniques seen in table 9.

\begin{tabular}{l} 
Table 9 Components of cognitive behavioral interventions \\
\hline Exposure \\
- Encourage patients to face fears \\
- Patients learn corrective information through experience \\
- Successful coping enhances self-efficacy \\
\hline Safety response inhibition \\
- Patients restrict their usual anxiety-reducing behaviors (e.g., \\
escape, need for reassurance) \\
- Decreases negative reinforcement \\
- Coping with anxiety without using anxiety-reducing behavior \\
enhances self-efficacy \\
\hline Cognitive strategies \\
- Cognitive restructuring, behavioral experiments, and related \\
strategies target patients' exaggerated perception of danger (e.g., \\
fear of negative evaluation in SAD) \\
- Provides corrective information regarding the level of threat \\
- Can also target self-efficacy beliefs \\
\hline Arousal management \\
- Relaxation, breathing control skills and biofeedback can help \\
- Patient control increased anxiety levels \\
knowledge of the location of the nearest toilet) \\
\hline Surrender of safety signals \\
\hline
\end{tabular}

Adapted according Katzman et al. (2014) 
Arousal management techniques are most often connected with treatment of specific fobia and coping with one's own vegetative dysbalance. However, principles of exposure might be utilised within the therapy whenever we need to train client's skills in a context of negative emotional interaction. Silverman and Curtiness (1997) say that the exposure therapy may be considered a current strategy or factor for many successful psychotherapies. At the same time, selfconfidence reached by means of own experience becomes strong and permanent (Bandura, 1982). Discovering the fact that a patient can learn something new and adaptive in a situation from which he has unexplainable phobia might be an "Aha effect Oh, I see!" experience that "liberates" him.

In spite of that some therapists avoid exposure methods intentionally. They consider exposure as unprofitable frustration of the client. However, they disregard the fact that the exposure is admittedly unpleasant within a short term context but within a long term horizon it might be absolutely enriching. Practically all the therapists want the therapy to be a safe place and at the same time they consider the exposure to be a dangerous, even cruel intervention. This attitude derogates both the therapists and their clients. One from strong prejudices which might make practicing of exposure more difficult is the fact that exposure destroys relationship between the therapist and the client. Many therapists think that if their client goes through artificially evoked anxiety, then the client will never have a positive relationship towards them. At the same time, they think that a productive therapeutic relationship allows positive feelings only with the therapy or towards therapy.

In other words, there is a belief that the therapy must be always pleasant for the client. However, there are many therapeutic approaches which are not compatible with this principle.

If the therapy is absolutely comfortable, on the contrary, it is less probable that there will be a positive change. A well-known saying cites: "Cat in gloves catches no mice". And it is well-known from general principles of learning that only training with maximal stress leads to a clinical effect (Cziksentmihályi, 1978 and 1990).

Stress is a survival mechanism, inherited from our ancestors to increase internal awareness of danger and transform all the body's resources to increase state of readiness. The autonomic nervous system is activated whether the threat is real or not. There are a number of ways that people respond to stressful situations in their lives, depending on their personalities, their cognitive style, their background and prior experiences. These responses reflect level of arousal autonomic nervous system and may divided to physiological, emotional and cognitive. People came to therapy when they are unable to tolerate the sign of acute or prolonged stress.

According Marra (2005) high emotional arousal is the cause of subsequent emotional disorders. The emotionally sensitive person reacts more intensively on environmental or internal cues, become hyper aroused and tends to scan environment for threat cues. This keeps emotional arousal high, causing internal discomfort.

High emotional arousal can be objectively measured by various psycho physiological modalities as muscular tension, breathing patterns, changes in skin conduction, increased heart rate, changes in heart rate variability and so on. People stress reaction is an individual response in different psycho physiological modalities.

The most used modality is skin conductance as a noninvasive and sensitive index of sympathetic cholinergic activity. The changes in electric conductivity of the skin are connected with fluctuations of sympathetic arousal connected with various stress stimulus and emotions. Critchley ( 2002) consider skin conductance as a sensitive psychophysiological index associated with emotional and cognitive conditons.

Strategies of a "prescriptive symptom" use to be very efficient because they prepare a client on experience of both a positive and negative emotions. Within exposure therapy client actively deals with experiencing negative feelings what minimize "inscrutability" of somatic anxiety equivalents. The client will become tough towards experiences of own stress and by it, he is consequently able to face his own anxiety. During the exposure, the client goes through anxious stimuli; he experiences emotional excitement and learns how habituate to anxiety. At the same time he trains and acquires various strategies how to cope with the given situation and how to obtain self -confidence.

Self-control is a main principle of non-pharmacological strategies that are applied in the treatment of a wide spectrum of mental disorders. Many so called psychosomatic disorders do not react on current and traditional medical approaches. Treatment by psychiatric drugs then seems to be the simplest solution of severe problems. However, in fact it may lead to practising avoidance behaviour and the client may rely on actions from the outside (on using psychotropic drugs) and remains passive. Especially in a case of anxiety disorders, this model is hazardous if benzodiazepines are medicated for a long time. On the contrary active self-controlled training leads to improvement of selfconfidence on the base of client's piece of knowledge that the client may reach self-control over own so far enigmatic vegetative reactions.

Self-control is a training method which utilise training for long-term positive changes in the area of behaviour, emotions, cognition and physiological reactions. According to well-known Thorndike's Law of Effect and Trial and Error Learning Theory (in Plháková, 2006) - if correct behaviour patterns are followed by satisfying consequences, such behaviour patterns are more likely to happen again. For the time being, there are constant discussions in progress on efficacy of biofeedback strategies as compared with classic psychotherapeutic approaches (see Prochaska, Norcross, 1999).

\section{Utilisation of virtual reality for phobias therapies}

According Krish at. al (2016) an increasing number of researchers have emphasised the advantages of virtual reality against in vivo exposure in clinical settings for a range of specific phobia types. They potential benefits are: feasibility, cost-effectiveness, high appeal to clients, and treatment of multiple phobias, increased control, confidentiality, and safety.

Concept of virtual reality is understood as complex users' interface that contains real time simulations by means of multi sensitive channels. These sensory modalities might be visual, audible, haptic, olfactive etc. (Chinnock, 1994). During therapy by means of virtual reality, a computer generates scenes that a patient watches by a special a pair of glasses and are wears a flection sensitive helmet. If the patient moves his/her head in any direction, sensors in the helmet record this movement and the scene generated by computer keeps changing in adequate way. For this purpose it is possible to use also special gloves that transmit a sense of touch and allow touching 
subjects in virtual world. Several research groups already referred to advantages of its utilisation and possible applications. We suppose that all clinical disciplines might utilise this method in future. Sutherland's study is one from the first research publications devoted to this theme (Sutherland, 1968). For the first time, the virtual reality was utilised for treatment of specific phobias as aerophobia, fear of heights or arachnophobia (Côté, Bouchard, 2008). In virtual reality the patient is step-by-step exposed to situations or objects that put the patient to fear. For example Lamson (in Hockenbury, Hockenbury, 2014) utilised virtual reality successfully for 60 patients who suffered from fear of heights. Great attention has been concentrated on questions connected with virtual reality utilisation within exposure therapy while treating anxiety disorders. Therapeutic effect of the exposure therapy by virtual reality has been demonstrated in a case of acrophobia (e.g. Emmelkamp, Krijn, Hulsbosch et al., 2002), arachnophobia (e.g. Garcia-Palacios, Hoffman, Carlin et al., 2002), claustrophobia (e.g. Botella, Banos, Villa et al., 2000), panic disorder and agoraphobia (e.g. North, North and J. Coble, 1997), social phobia (e.g. Lee, Ku, Jang et al., 2002) posttraumatic stress disorder (e.g. Rothbaum, Hodges, Ready, et al., 2001) and some others.

\section{Methodology}

Authors attempted to create modification of exposure therapy while utilising virtual reality at stimuli that are problematically trained within imaginative exposure and exposure in vivo by using psychophysiological measurement of the arousal level and adapt the stimulus to actual level of the fear.

Under collateral monitoring of some selected physiological parameters by means of multi-channel device Procomp Infinity intended for biofeedback made by Canadian Company of Thought Technology, the clients watched the screen that a feared stimulus was projected on. It dealt for example with an enraged barking dog behind a fence or a frightening view from the third floor.

Process of using exposure to virtual reality adapted to the level of arousal goes step by step from the less crushing stimuli through stronger stimuli up to the aiming point (e.g. from a view from the third floor up to a view from the seventh floor.).

The therapist firstly made the client acquainted with fear and stress response. He informed the client about the facts that these responses originally had adaptive function and they served for survival and therefore they are relatively common. On unprofessional level we might say that nowadays they are "correct responses at incorrect place". The therapist together with the client then created a vicious circle of corporal symptoms, negative thoughts, emotions and behaviour on which he described their correlation (Praško, Možný, Šlepecký et al, 2007). An important step was also explanation of available possibilities of therapies, encouragement of the client and reinforcement of a chance of complete recovery.

Training (the exposure therapy) led to gradual reduction of anxiety thanks to the fact that the client was repeatedly exposed to feared situations and gradually got accustomed to them.
The therapeutic process proceeded gradually by following steps.

The patients education on the fact that phobia is a treatable disease.

Education on the role of avoidance behaviour in perpetuating the disease and exposure therapy as a standardised treatment approach. During the education therapist must emphasize that it is necessary to spend sufficiently long time in feared situations in order that the anxiety could be noticeably eliminated. Otherwise anxiety is not sufficiently eliminated and is in fearful situation present again. The client will get used to it and will "become hardened". In the other words he/she will get accustomed to the anxiety.

Creation of fears hierarchy situation elicited only minor anxiety to the situation created the highest anxiety and then expose person gradually to feared situations step by step, firstly in imagination and then in vivo.

Clinical experiences dealing with difficulty of drills within "classical" cognitive-behavioural therapy led us to the following conclusions.

Many clients are not able to be imaginative and they rather avoid problems.

Exposure in vivo is not possible in all cases.

We do not have enough objective information on actual rating scale of anxiety in "classical" exposure therapy.

Methodology of measurement of anxiety rating scale on the base of subjective evaluation is not sufficient enough and is a subject to many variables including counter-transference towards the therapist.

\section{Exposure in vivo}

Graduated exposure

During graduated exposure the curve of anxiety should be measured in the course of time.

Monitored value: cutaneous conductivity

Improvement might be reached more quickly if the interval between exposures is short. It is ideal to expose a patient the feared situation once a day at least.

\section{Imaginal exposure}

Imaginal exposure is used as a preparation phase for exposure in vivo in a case of patients who suffer from very severe anxiety.

It might be also used as an autonomous method of phobias therapy. It is used in cases when it is impossible to train exposure in vivo systematically in gradual manner (phobias from thunderstorms, aerophobia or similar)

The process is similar as in the case of graduated exposure in vivo.

To be aware of this problems autors attempted to modify exposure therapy in virtual reality. At first they recorded videos with various feared situations that the client could watch. That way autors wanted to interconnect a rate of experienced anxiety with a specific incentive material that is accessible with difficulty in reality (taking a plane off, a parachute jump, thunderstorm or similar). Whereas the client was 
exhibited to the feared stimulus or situation in virtual reality, we measured physiological reactions that indicated a rate of extinction and tension by means of biofeedback modality - skin conductance. When the arousal caused by fear of stimulus was getting higher, the video presentation of fearful situation was getting smaller and so less frightful. After lowering the sympathetic reaction of autonomous nervous system the picture of fearful object was getting bigger.

Explanation: Barograph on the left shows actual level of skin conductance. The threshold is accustomed according the actual data. The size of the picture for training the fear of driving is changed according the actual trend of arousal. Going up make the picture smaller, going down make the picture larger. The graph on the left down shows the changes of skin conductance during 30 seconds. The barograph on the right shows the changes during periods of 20 seconds during the whole training

The process continues to the point when the level of arousal was less than half of starting measurement. So therapist get exact information if the exposure is sufficient enough to stop and move to next step. We suppose that without psychophysiological measurement would be difficult to find the point that the fear is low enough to stop the exposure. On the other side patient was able to interconnect his level of arousal with the moving size of stimulus video presentation and get the sense of controlling it. In the case when person reaction is in other modality we can use for instance skin temperature, or breathing rate. In that case the reaction is more prolonged and more stable.

In future we would like to concentrate not only on continuous monitoring of cutaneous conductivity but also on monitoring of Heart Rate Variability (HRV) and Respiratory Sinus Arrhythmia (RSA) and to strengthen virtual reality by vibration incentives e.g. imitation of vibrations during taking a plane off, respectively by more realistic acoustic quadraphonic production.

\section{Discussion}

Modification of exposure therapy by means of virtual reality under parallel measurement of some physiological parameters by biofeedback presents itself as a promising solution of treatment for some more complicated phobic disorders. It might be used for phobias that a client cannot be exposed to in reality because it is not technically possible.

Maladaptive responses of autonomous nervous system can be recorded and measured and, by biofeedback, the client gets continuous information on specific stress responses that are in progress in person's body and which transform themselves into body symptoms. For example the client becomes aware of raising blood pressure when he/she subconsciously hyperventilates. Within consequent training by means of biofeedback the patient learns how to obtain a control over these maladaptive responses. By gradual training the person learns how to habituate to anxiety and how to break anxious vicious circle. Because it deals with a skill that the patient acquired by own energy, the patient is consequently given

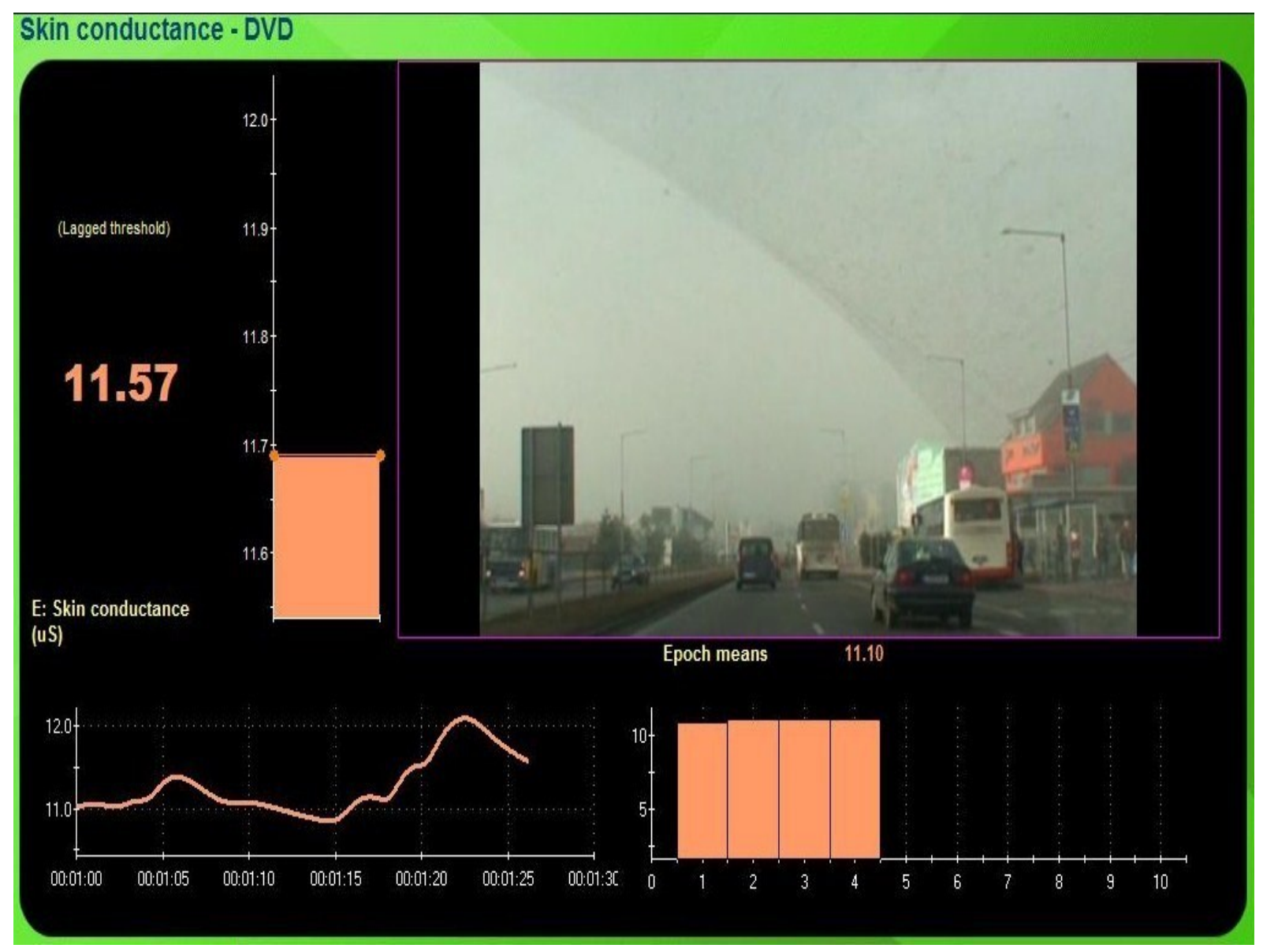

Picture 1: Virtual reality training 
higher self-confidence.

Thanks to connection of exposure therapy and virtual reality together with biofeedback we could offer the clients a well-structured, safe and controlled environment in which they could learn how to cope with the most fearful situations and how to obtain continuous information on efficacy of own sources and strategies of elimination of stress and anxiety.

We think that the modification of exposure therapy by means of virtual reality is a promising strategy especially in cases of anxious disorder where possibilities of exposure in vivo are complicated for example by natural phenomena (e.g. a thunderstorm) or completely excluded (e.g. a parachute jump from a plane or similar). Parsons and Rizzo (2008) in their meta-analysis also talk about an effect of exposure with 3D virtual reality. However, it deals with simple phobias without utilisation of biofeedback. Also Pina, Silverman, Weems et al (2003) investigated a similar subject-matter.

Of course, the method must be analysed and other comparative studies must be realised in order that its efficacy was demonstrated for complicated psychical discomforts and disorders.

\section{Conclusion}

In recent years, the therapy by virtual reality becomes an accepted way of specific phobias treatment and scientists start speculations about its application on anxious disorders as panic disorder (Meyerbröker, Emmelkamp, 2010). McLay et al. (2011) successfully utilised virtual reality for treatment of posttraumatic stress disorder. In conclusion, we may say that the virtual reality is easier and cheaper way of treatment as regards its realisation than the exposure in vivo executed in real conditions. Hockenbury and Hockenbury (2014) stress the fact that virtual reality may lead to situation where extremely phobic people are only able to start the treatment. GarciaPalacios et al. (2002) in their study found out that $80 \%$ of patients who suffer from arachnophobia preferred exposure by virtual reality to exposure executed by living spiders. Meyerbröker and Emmelkampem (2010) investigation shows that patients more often tend to finish earlier the therapy in which they are exposed to real objects than the therapy which utilise exposure by means of virtual reality.

\section{Literature:}

Bandura, A. (1982). The assessment and predictive generality of selfpercept of efficacy, Journal of Behavior Therapy and Experimental Psychiatry, _13 (3), September, 195-199.

C. Botella, R.M. Banos, H.Villa, C. Perpina and A. Garcia-Palacios (2000). Virtual Reality in the treatment of claustrophobic fear: a controlled multiple baseline design, Behavior Therapy, 31, 583-595.

Csikszentmihalyi, M. (1978). Intrinsic Rewards and Emergent Motivation in The Hidden Costs of Reward: New Perspectives on the Psychology of Human Motivation, eds Lepper, Mark R;Greene, David, Erlbaum: Hillsdale: NY 205-216.

Csikszentmihalyi, M. (1990). Flow: The Psychology of Optimal
Experience. New York: Harper and Row.

Côté, S., \& Bouchard, S. (2008). Virtual reality exposure's efficacy in the treatment of specific phobias: A critical review. Journal of Cyber Therapy and Rehabilitation, 1(1), 75-91.

Chinnock, C. (1994). Virtual reality in surgery and medicine, Hosp Technol Ser, 13, 1-48.

Critchley, H.D. 2002. Electrodermal Responses: What Happens in the Brain. In Neuroscientist. 2005, vol. 8, no. 2, p. 577-597

Emmelkamp, P., M., G., Krijn, M., Hulsbosch, A.M. et al. (2002). Vitual reality treatment versus exposure in vivo: a comparative evaluation in acrophobia, Behaviour Research and Therapy, 40, 509-516.

Garcia-Palacios A., Hoffman, H.G., Carlin, A. et al. (2002). Virtual Reality in the treatment of spider phobia: A controlled study, Behaviour Research \& Therapy, 40, 983- 993.

Hockenbury, D. H., \& Hockenbury, S. E. (2014). Discovering Psychology. New York: Worth Publishers.

Lee, J.M., Ku, J.H., Jang, D.P. et al. (2002). Virtual reality system for treatment of the fear of public speaking using image-based rendering and moving pictures, Cyberpsychology and Behavior, 5, 191-195.

Katzman et al. Canadian clinical practice guidelines for the management of anxiety, posttraumatic stress and obsessive-compulsive disorders BMC Psychiatry 2014, 14(Suppl 1):S1

http://www.biomedcentral.com/1471-244X/14/S1/S1

Lewandowski, G.; Strohmetz, D. (2009). Actions can speak as loud as words: Measuring behaviour in psychological science, Social and Personality Psychology Compass, 3 (6): 992-1002.

McLay, R. N., Wood, D. P., Webb-Murphy, J. A., Spira, J. L., Wiederhold, M. D., Pyne, J. M., \& Wiederhold, B. K. (2011). A randomized, controlled trial of virtual reality graded exposure therapy for posttraumatic stress disorder in active duty service members with combat-related post-traumatic stress disorder. Cyberpsychology, Behavior, and Social Networking, 14(4), 223-229.

Meyerbröker, K., \& Emmelkamp, P. M. G. (2010). Virtual reality exposure therapy in anxiety disorders: A systematic review of process and-outcome studies. Depression and Anxiety, 27(10), 933944. 
Meyers, D. (2008). Psychology. New York: Worth Publishers.

M. North, S. North and J. Coble (1997). Virtual reality therapy, I.P.I. Press, Ann Arbor, Michigan.

Parsons,T.D., Rizzo, A.A. (2008). Affective outcomes of virtual reality exposure therapy for anxiety and specific phobias : A meta-analysis. Jounal of Behavioral Therapy and Experimental Psychiatry. 39, 250261.

Praško, J., Možný, P., Šlepecký, M. a kol. (2007). Kognitivně behaviorální terapie psychických poruch. Kroměříž: Triton.

Prochaska J.,O., Norcross J., C. (1999): Psychoterapeutické systémy. Grada, Praha

Pina, A., A.; Silverman, W., K.; Weems et al. (2003). A comparison of completers and noncompleters of exposure-based cognitive and behavioral treatment for phobic and anxiety disorders in youth, Journal of Consulting and Clinical Psychology, 71(4), 701-705.

Rothbaum, B.0., Hodges, L., F., Ready et al (2001). Virtual reality exposure therapy for Vietnam veterans with posttraumatic stress disorder, Journal of Clinical Psychiatry, 62, 617-622.

Sutherland, I. (1968). A head-mounted three dimensional display, FCCC, $33,757-764$. 